\title{
STRATEGI PENERJEMAHAN SUBTITLING DALAM FILM "ENDER'S GAME"
}

\author{
Endang Sulistijani ${ }^{1}$, Friza Youlinda Parwis ${ }^{2}$ \\ Program Studi Pendidikan Bahasa Indonesia, \\ Fakultas Bahasa dan seni, Universitas Indraprasta PGRI \\ lendang711@yahoo.co.id
}

\begin{abstract}
Abstrak
Terjemahan sangat penting bagi perkembangan ilmu pengetahuan di segala bidang. Penelitian ini mengambil objek terjemahan pada subtitling film "Ender's Game". Tujuan penelitian ini adalah untuk mengidentifikasi strategi penerjemahan apa saja yang terdapat dalam subtitling film "Ender's Game". Strategi apa yang paling dominan dan ketepatan makna serta kesesuaian dengan durasi waktu film tersebut. Penelitian ini merupakan penelitian deskriptif kualitatif dengan teknik purposive sampling. Dari penelitian ini dapat diketahui bahwa strategi terjemahan yang digunakan dalam film "Ender's Game" adalah strategi penambahan, paraphrase, transfer, imitasi, pemampatan, desimasi, penghapusan, dan penjinakan. Dalam film "Ender's Game", strategi pemampatan paling sering digunakan. Hal ini disebabkan oleh keterbatasan durasi ruang dan waktu dalam film sehingga subtitling harus hemat kata-kata. Namun, hal ini tidak mengurangi kesesuaian dengan makna bahasa sumber dan tetap memperhatikan budaya sasaran. Untuk kata-kata yang kurang sesuai dengan budaya sasaran dapat digunakan strategi penjinakan (taming)
\end{abstract}

Kata Kunci: terjemahan, subtitling, film "Ender's Game”, strategi terjemahan

\begin{abstract}
Translation is very important for the development of knowledge in all fields. This research has taken the translation object on the subtitling of "Ender's Game" movie. The purpose of this study is to find out how translations are used in the subtitling of the "Ender's Game" movie. What is the most dominant strategy and accuracy of meaning and suitability with the duration of the film. This study uses a qualitative descriptive approach and purposive sampling technique. The results showed that the translation used in the film "Ender's Game" was an additional strategy, paraphrasing, transfer, imitation, compression, desimation, deletion, and taming. From the existing strategy, the most prominent compression strategy. This is due to the limited hidden space and time of subtitling in subtitling, which should save translation. However, it does not reduce conformity with the meaning of language and continue to pay attention to the target culture. For words that are not in accordance with the target culture, taming strategies can be used.
\end{abstract}

Keywords: translation, subtitling, film “Ender's Game”, translation strategy

\section{PENDAHULUAN}

Perkembangan ilmu pengetahuan dan teknologi sangat berkaitan pula dengan perkembangan penerjemahan. Penerjemahan berkembang pesat tidak hanya dalam penerbitan buku-buku saja tetapi juga penerjemahan dalam film.
Sebelum abad 20 penerjemahan hanya digunakan dalam bidang keagamaan, sastra, ilmu pengetahuan dan teknologi. Namun, sejak abad 20 penerjemahan sudah merambah ke semua bidang termasuk audiovisual. 
Bidang audiovisual seperti mendengarkan pidato, ceramah, dalam konferensi, media sosial, dan film merupakan bidang yang berkaitan dengan penerjemahan. Penerjemahan film sangat dibutuhkan karena masyararakat tidak hanya ingin menikmati film-film dalam negeri saja, tetapi juga film dari berbagai Negara. Abad 21 industri perfilman semakin berkembang di Asia seperti Indonesia, Korea, Thailand, Jepang, India, dan sebagainya. Penerjemahan film dibagi dua, yakni dubbing dan subtitling. Hal ini seperti yang dinyatakan oleh Boordwell \& Thompson, "The most two common forms form of screen translation are dubbing and subtitling" (Bordwell \& Thompson, 1990: 409).

$$
\text { Lebih lanjut Thomson }
$$

menyatakan, "Dubbing as the process of replacing part or all of the voices on the sountrack in order to correct mistakes or rerecord dialog". Yang dimaksud adalah dubbing sebagai proses penggantian bagian suara pada soundtrack untuk memperbaiki kesalahan atau merekam kembali dialog tersebut. Thomson menambahkan bahwa sulih suara tidak terjadi dari satu bahasa (Bahasa Sumber) ke bahasa lain (Bahasa Sasaran) atau SL (Source Language) into TL (Target Language) saja, tetapi dapat terjadi dari SL ke TL dengan suara orang yang berbeda. Hal ini sedikit berbeda dengan subtitling. Gambier menyatakan, "Subtitling is one of two possible methods for providing the translation of a movie dilaogue, where the original dialogue soundtrack is left in place and the translation is printed along the bottom of the film (Gambier, 1993: 276).

Dengan kata lain, subtitling adalah terjemahan pada dialog film yang diletakan di bawah film tersebut. Tujuan subtitling ini untuk membantu pemirsa menikmati sebuah film berbahasa asing. Pakar lain, Betty White, mengatakan "subtitling is the translation of the spoken language (source language) of a television program or film into target language.

The translated text usually appears in two lines at the bottom of the screen

Menurut Betty, subtitling merupakan terjemahan dari bahasa sumber dalam program televisi atau film ke bahasa target. Dijelaskan pula bahwa dalam subtitling tidak boleh lebih dari dua baris. Penerjemahan dari bahasa sumber ke bahasa target tidak lepas dari "teks. Maksudnya, dalam penerjemahan, sangat diperhatikan konteks situasi dan budaya (White, 2008).

Dari pemahaman tentang lintas budaya (Cross Culture Understanding) akan ditemukan ideologi teks tersebut. Selain itu, teks juga berkaitan dengan field (isi), mode/channel (lisan/tulis), dan tenor/relation (hubungan antara pembicara-pendengar/pemirsa atau penulis-pembaca. Seorang penerjemah harus mampu memilih strategi penerjemahan secara tepat dengan memperhatikan konteks situasi dan pemahaman lintas budaya.

Apalagi dalam subtitling, penerjemah berhadapan dengan suatu fenomena unik, yaitu teks bahasa sumber merupakan teks dari dialog lisan yang didukung oleh setting tempat, waktu, suasana, ilustrasi musik, mimik tokoh, dan sebagainya.

Tujuan penelitian ini untuk mengetahui startegi penerjemahan yang dipakai dalam film "Ender's Game" tersebut. Selain itu, dapat diketahui juga strategi penerjemahan yang sangat dominan dalam penerjemahan subtitling film "Ender's Game" dan apa penyebabnya.

Manfaat penelitian ini dipandang dari dua sisi dimensi, yakni dimensi pengembangan kajian penerjemahan dan dimensi praktis. Dari dimensi 
pengembangan kajian penerjemahan, hasil penelitian ini diharapkan membantu peneliti penerjemahan melakukan kajian berbasis analisis teks dalam penerjemahan pada berbagai jenis teks.

Dari dimensi praktis, hasil penelitian ini diharapkan dapat bermanfaat bagi penerjemah untuk menganalisis teks dengan lebih kritis dan dapat memilih strategi yang tepat sehingga mampu menghasilkan terjemahan yang sesuai dengan tujuan penerjemahan dan dapat diterima oleh pembaca TL. Dengan strategi penerjemahan yang tepat pula, kualitas terjemahan semakin lama semakin baik dan meningkat.

Berikut ini diuraikan beberapa definisi terjemahan, proses terjemahan, dan strategi terjemahan.

Menurut Larson, penerjemahan merupakan pengalihan makna dan penggantian bentuk bahasa dari bahasa sumber ke bahasa target. Bentuk dapat diubah, tetapi makna harus dipertahankan (Larson, 1998).

Larson juga menjelaskan bahwa yang dimaksud dari menerjemahkan adalah (a) mempelajari teks bahasa sumber yang di dalamnya terdapat struktur gramatikal, leksikonnya, konteks situasi dan budaya; (b) menganalisis teks bahasa sumber untuk mengetahui maknanya; (c) menyatakan kembali makna yang sama dengan leksikon, struktur gramatikal, konteks situasi dan budaya ke dalam bahasa target.

Menurut Nida dan Taber, penerjemahan merupakan pernyataan kembali isi atau pesan dari bahasa sumber ke bahasa target dengan padanan yang sama atau mendekati terutama makna dan gaya bahasanya. Tujuan utama penerjemahan adalah mengungkap kembali pesan. Agar maksud pesan yang diungkapkan dapat diterima oleh pendengar/pemirsa atau pembaca dengan benar, penerjemah harus dapat menyesuaikan gramatikal dan leksikonnya dengan baik pula (Nida $\&$ Taber, 1969).

Kesepadanan makna merupakan hal penting dalam penerjemahan. Ini adalah sebuah reproduksi pesan bukan hanya pemindahan bentuk. Jadi, makna harus diutamakan dalam penerjemahan dan isi pesan adalah keutamaan yang mendasar. Catford menekankan terjemahan pada medium yakni melihat terjemahan sebagai pengalihan bahasa atau "an operation performed on language: a process of substituting a text in one langauge for a text in another".

Selanjutnya, Catford menambahkan pula bahwa translation is the replacement of textual material in one language (SL) by equivalent textual material in another language (TL) (Catford, 1965: 1)

Terjemahan adalah pengalihan materi testual dari bahasa sumber dengan materi tekstual yang sepadan dari bahasa target.

\section{Strategi Penerjemahan}

Beberapa pakar penerjemahan menggunakan istilah yang berbeda untuk menyebut "strategi penerjemahan". Vinay dan Dalbernet (Vinay \& Darbelnet, 2000) serta Bakee (Baker, 1992) menyebutnya 'strategi'. Hoed (Hoed, 1992)menyebut istilah tersebut dengan 'teknik', sedangkan Newmark (Newmark, 1981) menyebut dengan istilah 'prosedur'. Menurut Newmark, strategi penerjemahan digunakan untuk menangani masalah-masalah penerjemahan dalam kata, tingkat frasa, dan kalimat. Berikut beberapa strategi yang dapat digunakan penerjemah untuk mengatasi masalah penerjemahan (Newmark, 1981).

\section{Transferensi}


Transferensi adalah strategi penerjemahan yang menggunakan istilah Tsu ke dalam Tsa. Baker (Baker, 1992) menyebutkan translation using loan words, Vinay dan Darbelnet (Vinay \& Darbelnet, 2000) menyebutnya borrowing, dan Hoed menyebutnya 'tidak diberikan padanan' (Hoed, 1992).

Strategi ini digunakan untuk memperkenalkan kata/ istilah asing. Misalnya, nama makanan 'hamburger' dan 'pizza' yang tetap dipertahankan dalam Tsa karena belum memiliki padanan dalam Bsa (Bahasa Sasaran).

\section{Naturalisasi}

Naturalisasi merupakan strategi penerjemahan dengan cara mengadaptasi istilah atau kata dalam bahasa sumber ke dalam pelafalan dan struktur morfologi yang alami dari bahasa sasarannya (Newmark, 1981). Sementara Hoed memakai istilah 'penerjemahan fonologi' untuk strategi ini (Hoed, 1992).

Menurutnya, strategi penerjemahan fonologis digunakan apabila penerjemah tidak mendapatkan kesamaan yang tepat $\mathrm{BSa}$ sehingga diputuskan untuk memunculkan istilah baru yang diambil dari bunyi kata itu dalam BSu untuk disesuaikan dengan sistem bunyi (fonologi) dan ejaan (grafologi) BSa. Sebagai contoh, 'cryptographic

\section{Kalke (Calque)}

Menurut Newmark dan Vinay \& Dalbernet, calque atau through translation adalah penerjemahan literal yang memakai pinjaman untuk kolokasi yang umum dan mungkin frasa yang sudah dikenal oleh pengguna BSa. Misalnya, 'honeymoon' diterjemahkan menjadi 'bulan madu'. Frasa dalam bahasa sumber ini diterjemahkan secara literal. Dari teknik ini terlihat adanya interferensi struktur bahasa sumber.
Karena tidak ada padanannya, frasa tersebut diterjemahkan sesuai dengan bentuknya. Jadi, mirip dengan teknik peminjaman murni dan alamiah. Perbedaannya adalah bahwa teknik ini biasanya digunakan dalam tataran frasa tetapi tidak mengubah susunan katanya (word-for-word translation) atau mengubah susunan kata (literal translation), tetapi dengan meminjam istilah aslinya (Newmark, 1981; Vinay \& Darbelnet, 2000).

\section{Modulasi}

Strategi modulasi adalah variasi dalam penerjemahan dengan cara mengganti cara berpikir atau sudut pandangnya (Vinay \& Darbelnet, 2000). Dengan strategi modulasi ini, hal yang abstrak dapat diubah menjadi konkret, kalimat aktif dapat diubah menjadi kalimat pasif, simbol atau lambang dapat diganti, dan sebagainya. Sejalan dengan pendapat Vinay dan Dalbernet serta Hoed berpendapat dalam modulasi penerjemah memberikan padanan yang secara semantis berbeda sudut pandang maknanya atau cakupan maknanya, tetapi dalam konteks yang bersangkutan memberikan kesan atau maksud yang sama. Sebagai contoh, 'tea bag' diterjemahkan menjadi 'teh celup' (Hoed, 1992; Vinay \& Darbelnet, 2000).

\section{Padanan Budaya}

Baker berpendapat bahwa padanan budaya atau kesesuaian budaya dapat dilakukan dengan mengganti kata atau ekspresi budaya BSu dengan kata atau ekspresi budaya yang berbeda di $\mathrm{BSa}$, tetapi memiliki maksud dan dampak yang sama bagi pembaca BSa. Misalnya, dengan disertai contoh-contoh yang sepadan dengan budaya bahasa sasaran/target (Baker, 1992). Sejalan dengan pendapat Baker, Newmark (1988) menjelaskan dengan strategi ini penerjemah mengganti kata budaya 
dalam BSu dengan kata budaya yang sepadan dalam BSa (Baker, 1992; Newmark, 1981). Misalnya, dalam film Laskar Pelangi terdapat adegan dan dialog tokoh utama mengagumi Raja Dangdut Rhoma Irama. Dalam bahasa target dapat ditambahkan dengan frasa like Elvis Presley, the king of music. Misalnya, 'manor born' diterjemahkan menjadi 'berdarah biru' atau 'berdarah bangsawan'.

\section{Kesepadanan Deskripstif}

Menurut Hoed, kesepadanan deskriptif adalah strategi penerjemahan dengan memadankan kata atau istilah dari bahasa sumber $(\mathrm{BSu})$ disertai uraian secara jelas pada bahasa sasarannya (BSa). Strategi ini digunakan apabila penerjemah tidak menemukan istilah yang sepadan dari BSu ke dalam BSa. Sebagai contoh, 'licensed software' diterjemahkan menjadi 'perangkat lunak yang dilisensikan’ (Hoed, 1992).

\section{Kata Generik}

Strategi penerjemahan dengan kata generik ini digunakan apabila menemukan kesulitan dalam mencari kata yang lebih spesifik dalam bahasa sasaran sebagai padanan kata dalam bahasa sumber (Baker, 1992). Hal senada juga diungkapkan oleh Larson, kata generik dapat digunakan apabila kata yang lebih spesifik tidak ditemukan dalam BSa. Larson memberi contoh apabila padanan kata 'wolf' tidak ditemukan dalam $\mathrm{BSa}$, kata yang lebih umum 'animal' dapat digunakan (Larson, 1998).

\section{Penjelasan Tambahan}

Penjelasan tambahan diberikan agar suatu kata dapat lebih mudah dipahami oleh pembaca Tsa. Menurut Hoed, istilah atau kata yang disertai dengan deskripsi tambahan merupakan kata yang masih dianggap asing oleh pendengar/pemirsa/pembaca $\quad \mathrm{BSa}$ (Hoed, 1992). Contohnya, nama makanan, minuman,merek, istilahistilah yang memiliki kekhasan budaya yang tidak ada dalam bahasa sasaran (BSa). Baker menjelaskan bahwa deskripsi tambahan dapat disejajarkan dengan kata pinjaman atau loan words plus explanation. Penjelasan tambahan dipakai untuk menerjemahkan konsep budaya, konsep modern, dan kata-kata yang tidak umum. Misalnya, 'Cheerios' diterjemahkan menjadi 'sereal Cheerios' (Baker, 1992).

\section{Penerjemahan dengan Pengurangan}

Baker berpendapat strategi ini mungkin terdengar agak berani, tetapi sebenarnya tidak terlalu berbahaya untuk mengurangi terjemahan kata atau ekspresi pada konteks tertentu. Apabila makna yang terdapat dalam kata atau ekspresi tidak terlalu penting dalam keseluruhan teks dan malah akan membuat pembaca bingung dengan penjelasan yang panjang lebar, penerjemah dapat menghilangkan terjemahan kata atau ekspresi yang dimaksud (Baker, 1992).

\section{Terjemahan Resmi}

Hoed mengungkapkan istilah terjemahan resmi (Hoed, 1992). Newmark menyebutnya recognized translation. Dengan strategi ini, penerjemah tidak perlu mencari padanan untuk sejumlah istilah, nama, dan ungkapan yang telah memiliki padanan resmi dari bahasa sasarannya karena dalam terjemahan resmi sudah ada padanan yang strandar. Misalnya dalam menerjemahkan istilah dalam teks undang-undang, Al Quran, Injil, glosari di bidang tertentu, penerjemah dapat langsung menggunakan terjemahan resmi yang sudah ada (Newmark, 1981). Newmark bahkan menekankan penerjemah tidak diharapkan menambah 
atau memperjelas terjemahan teks-teks itu (Newmark, 1981).

\section{Catatan Kaki}

Catatan kaki merupakan salah satu strategi penerjemahan yakni dengan memberikan penjelasan tambahan. Hoed berpendapat dalam catatan kaki, penerjemah membubuhkan penjelasan dalam bentuk catatan pada bagian bawah halaman. Tujuannya adalah agar makna terjemahan menjadi jelas dan mudah dipahami oleh pembaca, pendengar/pemirsa. Hal ini dilakukan apabila catatan itu panjang sehingga kalau ditempatkan di dalam teks akan mengganggu pembacaan (Hoed, 1992).

\section{Pengertian Subtitling}

Subtitling adalah proses penerjemahan teks film. Shuttleworth dan Cowie menyatakan bahwa subtitling isthe process of providing synchronized captions for film and television dialogue (and more recently for live opera) (Shuttleworth \& Cowie, 1997). O'Connel menjelaskan bahwa subtitling is defined as supplementing the original voice soundtrack by adding written text (O'Connell, 1998). Menurut Luyken, "Subtitling are condensed translations of original dialogue, which appear as lines of text usually positioned towards the bottom of the screen. The subtitles follow the rhythm of the original and appear and disappear synchronised with the corresponding section of original dialogue." Subtitle merupakan teks terjemahan yang mengacu pada dialog asli, yang kemunculannya sebagai deretan teks ditempatkan di bagian bawah dari film tersebut (Luyken \& Herbst, 1991).

Jadi, subtitling adalah pengalihan pesan lisan dari bahasa sumber $(\mathrm{BSu}) \mathrm{ke}$ bahasa sasaran (BSa) yang berbentuk tulis atau teks dimunculkan saat dialog berlangsung. Pembuatan subtitling pada film tidaklah mudah karena terikat oleh media dan waktu. Media yang dimaksud adalah layar film yang merupakan ruang untuk penemparan teks terjemahan. Hal ini tidak seperti teks terjemahan bahasa tulis yang ruang untuk teks terjelaman berupa halaman per halaman dalam buku atau novel. Tata letak penempatan subtitling meliputi posisi layar ada di bagian bawah, jumlah baris maksimal dua baris, tidak lebih dari 35 karakter per barisnya. Dari sisi waktu, penerjemah berhadapan dengan sulitnya menentukan waktu pemunculan subtitling karena harus tepat dengan kemunculan dialog. Beberapa ketentuan terkait dengan waktu munculnya subtitling, yaitu: a) 3 sampai 6 detik durasi untuk dua garis penuh; b) kurang dari 3,5 detik durasi satu baris tunggal (7 hingga 8 kata); c) 1,5 detik durasi satu kata tunggal; d) 0,25 detik waktu munculnya subtitling sesudah ujaran tokoh; e) 2 detik waktu subtitling hilang sesudah ujaran tokoh; f) waktu antara dua subtitling berturutan adalah 0,25 detik; g) dan subtitling harus menghilang sebelum "cut" karena "cut" menunjukkan perubahan tematik (Hastuti, 2015).

\section{Jenis-Jenis Subtitling}

Gottlieb membagi subtitling menjadi dua, yaitu intralinguistik dan interlinguistic (Gottlieb, 1994).

\section{Intralinguistik}

Intralinguistik adalah bentuk subtitling yang vertikal karena penampilan subtitling disesuaikan dengan bahasa asli. Jika terdapat perubahan hanya dalam bentuk mode karena mengubah pesan lisan ke bentuk teks/ tulis. Bentuk subtitling ini diterapkan pada program televisi lokal, khususnya untuk pemirsa yang pendengarannya kurang atau terganggu. Selain itu, dapat juga diterapkan pada program pembelajaran bahasa asing. 


\section{Interlinguistik}

Interlinguistik merupakan bentuk subtitling yang bersifat diagonal karena penerjemah mentrasfer pesan lisan ke dalam bahasa asing sehingga terjadi perubahan mode dan bahasa.

Sementara itu, berdasarkan segi teknisnya subtitling dibagi menjadi dua bagian, yaitu closed subtitling dan open subtitling seperti berikut ini (O'Connell, 1998).

\section{Closed Subtitling}

Jenis ini muncul dalam bentuk teletext yang bersifat pilihan artinya bahwa teks bisa dimunculkan atau tidak sesuai dengan keinginan penonton.

\section{Open Subtitling}

Open subtitling adalah jenis subtitling yang sering ditemukan pada program televisi. Penonton tidak dapat menghilangkan subtitling yang terdapat dalam film tersebut. Dengan kata lain, subtitling tersebut muncul dan menyatu dengan film.

\section{Strategi Penerjemahan pada Film}

Strategi penerjemahan dalam subtitling film pada dasarnya sama dengan pada buku, hanya saja ada beberapa tambahan strategi karena yang dihadapi penerjemah bukan teks tetapi dialog audiovisual. Menurut Gottlieb dalam Sugeng Haryanto Strategi penerjemahan untuk menerjemahkan film ada sebelas strategi. Sebelas strategi penerjemahan tersebut adalah sebagai berikut (Haryanto, 2005).

\section{Penambahan (expansion)}

Penambahan dalam penerjemahan berarti menambah keterangan dalam terjemahannya, contohnya kalimat That's in the dead-duck day diterjemahkan menjadi "Itu terjadi di bebek mati (Saat itu seekor bebek mati karena kena lemparanku)".

\section{Parafrase (paraphrase)}

Pada strategi paraphrase ini, penerjemah menjelaskan bagian kalimat berdasarkan apa yang dipahami si penerjemah. Contohnya, Turn back no longer diterjemahkan menjadi "Jangan lagi melihat masa lalu”.

\section{Transfer}

Strategi transfer ini terlepas dari penjelasan tambahan. Jadi, penerjemahannya harafiah, apa adanya. Penerjemah tidak mengubah dari sudut pandangnya atau penafsiran-penafsiran lain. Misalnya, Turn back no longer diterjemahkan menjadi "Jangan lagi melihat-melihat ke belakang".

\section{Imitasi}

Imitasi adalah suatu strategi penerjemahan dengan cara menulis kembali kata dalam teks aslinya tanpa ada penambahan. Hal ini digunakan untuk menuliskan nama orang atau nama tempat. Transkripsi Pada strategi ini penerjemah menulis ulang penggunaan kata atau istilah tertentu yang tidak umum dalam bahasa sumber. Sebagai contoh, BSu (Bahasa Sumber): Assalamualaikum wr.wb, dalam bahasa sasaran (BSa): Assalamualaikum wr.wb (Moslem greeting)

\section{Pemampatan (condensation)}

Strategi ini dilakukan dengan meringkas naskah asli untuk menghilangkan dialogdialog yang tidak penting. Namun demikian, pemampatan terjemahan bisa membuat hilang efek pragmatik padahal maksud asli naskah atau tokoh harus tersampaikan.

\section{Desimasi}

Desimasi adalah pemampatan yang ekstrem. Hal ini biasanya digunakan untuk menerjemahkan dialog tokoh yang mengeluarkan kata-kata tidak sopan, 
kurang mendidik karena tokoh sedang mengumpat atau bertengkar.

\section{Penghapusan (deletion)}

Pada strategi penghapusan ini sebagian naskah asli dihapus karena bagian tersebut hanya tambahan saja dan apabila dihapus tidak mengurangi makna keseluruhan teks. Perbedaan antara pemampatan dan penghapusan, yaitu dalam pemampatan terdapat bagianbagian yang dimampatkan atau dipadatkan, dibuat menjadi lebih sederhana tanpa mengurangi maknanya, sedangkan dalam penghapusan terdapat bagian yang sengaja dihilangkan atau dipotong agar tidak terlalu panjang atau lebih efektif.

\section{Penjinakan (Taming)}

Taming digunakan untuk menerjemahkan kata-kata yang kasar sehingga menjadi kata-kata yang bisa diterima oleh pemirsa.

\section{Pelepasan/Angkat Tangan (Resignation)}

Resignation ini diterapkan apabila tiada padanan terjemahan yang sesuai dan wujud kehilangan makna.

\section{METODE PENELITIAN}

Penelitian ini merupakan penelitian deskriptif kualitatif. Sumber data dalam film ini adalah subtitle film "Ender's Game" dan untuk menentukan kualitas terjemahan film tersebut, data diambil dari 10 rater. Peneliti menggunakan berbagai sumber untuk menguji kebenaran data yang sama.

Data yang diteliti berasal dari teks bahasa sumber (BSu), teks bahasa sasaran (BSa) dan para informan yang mengisi kuesioner (rater). Dari hasil kuesioner yang diambil berkaitan dengan strategi penerjemahan film "Ender's Game", terdapat 100 data yang masuk. Dengan teknik analisis isi dan kuesioner, dapat ditentukan strategi penerjemahan yang digunakan.

Teknik analisis dilakukan dengan cara menyimak, membaca, dan mencatat. Dalam penelitian ini, penulis menggunakan beberapa teori terjemahan dari Nida dan Taber, Larson, serta strategi terjemahan dari Newmark, Vinay, dan Baker.

\section{HASIL DAN PEMBAHASAN}

Strategi terjemahan dalam Subtitling Film "Ender's Game"

\section{Penambahan (Expansion)}

Contoh terjemahan dengan strategi penambahan (expansion):

a) Ender: Ten of millions died.

Ender: Sepuluh juta orang tewas.

b) Sersan Dap: At ease!

Sersan Dap: Istirahat di tempat!

Pada kutipan dialog contoh (a) terdapat penambahan kata "orang" yang seharusnya cukup dengan terjemahan sepuluh juta telah tewas. Hal ini karena penerjemah ingin menekankan siapa yang telah tewas, yaitu orang yang mati akibat serangan alien. Pada contoh (b) kata At ease seharusnya cukup diterjemahkan dengan kata "istirahat!" tapi kata ini diucapkan Sersan Dap setelah ketua barisan menyiapkan barisannya. Dalam budaya Indonesia, perintah yang digunakan dalam barisan untuk istirahat, digunakan kata "istirahat di tempat".

\section{Parafrase (Paraphrase)}

Contoh Parafrase:

a) Bonzo: You better watch your back, Wiggin.

Bonzo: Sebaiknya kau tak berulah, Wiggin.

b) Alai: Eat that! Dragon rules!

Alai: Makan itu! Dragon hebat! 
Strategi parafrase terlihat pada contoh kalimat di atas (a) yang diterjemahkan menjadi "sebaiknya kau tak berulah, Wiggin" Sebenarnya kalimat You better watch your back, Wiggin mempunyai maksud memberi peringatan agar Wiggin menjaga sikap. Pada kalimat (b) frase Dragon rules diterjemahkan menjadi "Dragon hebat". Yang dimaksud adalah Kelompok Dragon tersebut menguasai peringkat / menguasai game.

\section{Transfer}

Contoh strategi transfer.

Stilson: Don't lecture me, Wiggin!

Stilson: Jangan kuliahi aku, Wiggin!

Pada kalimat di atas terlihat jelas bahwa penerjemah menerjemahkan kalimat tersebut secara harafiah (apa adanya). Lecture berarti "kuliah" atau dalam bahasa Indonesia sepadan dengan kata "memberi kuliah/menguliahi".

\section{Imitasi}

Contoh strategi imitasi:

a) Peter: Stay out of the way, Valentine! Peter: Jangan ikut campur, Valentine!

b) Alai: Eat that! Dragon rules!

Alai: Makan itu! Dragon hebat!

Contoh kalimat (a) pada bahasa sumber terdapat kata-kata yang berhubungan dengan nama orang, yaitu Valentine. Untuk nama orang tersebut, penerjemah tetap menggunakan "Valentine".

Pada kalimat (b) terdapat kata Dragon yang mengacu pada nama kelompok, sehingga penerjemah tetap menulis ulang kata "Dragon" tanpa ada perubahan.

\section{Transkripsi (Transcription)}

Dalam penelitian ini tidak ditemukan adanya penggunaan strategi transkripsi.

\section{Pemampatan (Condensation)}

Contoh strategi pemampatan:

Sersan Dap: Wakie, wakie, rise and shine!

Sersan Dap: Bangun dan bersiaplah!

Strategi pemampatan yang terdapat pada contoh di atas dengan cara meringkas kalimat atau ucapan yang tidak penting sangat tepat agar pembaca atau pendengar tahu secara efektif makna yang akan disampaikan (tidak bertele-tele). Kata wakie (wake up) dan rise merupakan kata yang bermakna sama, yaitu "bangun", sehingga penerjemah memampatkan menjadi satu kata saja.

\section{Desimasi}

Contoh strategi desimasi:

Nurse: The sooner we get this done, the sooner you move on.

Nurse: Semakin cepat selesai, semakin cepat pulih.

\section{Strategi desimasi di atas digunakan penerjemah untuk pemampatan yang langsung mengena pada tujuan dengan maksud segera dilakukan agar cepat sembuh}

\section{Penghapusan (Deletion)}

Contoh terjemahan dengan strategi penghapusan:

Kolonel Graff: You're flapping around like a bunch of drunken ducks

Kolonel Graff: Kalian mengepak ngepak seperti sekumpulan bebek.

Pada contoh di atas, penerjemah sengaja menghilangkan kata around karena flapping around sama maksudnya dengan kata flapping, sedangkan kata drunken dihilangkan karena tidak ada padanan yang tepat dalam bahasa Indonesia 


\section{Penjinakan}

Contoh strategi penjinakan.

Bonzo: Are you threaten me, Snot? Bonzo: Apa kau mengancamku?

Strategi penerjemahan kalimat di atas menggunakan strategi penjinakan agar maknanya lebih berterima di budaya sasaran. Secara harafiah, kalimat Are you threaten me, Snot? apabila diterjemahkan akan menjadi "Apa kau mengancamku, Ingusan?".

Dari 100 data yang didapat dari kuesioner, strategi penerjemahan dalam film "Ender's Game" yang berdurasi satu jam 50 menit ini meliputi $11 \%$ penambahan, $8 \%$ parafrase, $12 \%$ transfer, $15 \%$ imitasi, $20 \%$ pemampatan, $12 \%$ desimasi, $12 \%$ penghapusan, dan $10 \%$ penjinakan. Untuk strategi penerjemahan transkripsi dan angkat tangan atau resignation, tidak ditemukan dalam subtitling tersebut.

\section{SIMPULAN}

Simpulan dari analisis yang telah dipaparkan, maka strategi terjemahan yang digunakan untuk menerjemahkan film "Ender's Game" adalah strategi penambahan, parafrase, transfer, imitasi, pemampatan, desimasi, penghapusan, dan penjinakan. Di antara kedelapan strategi tersebut, strategi pemampatan yang paling dominan.

Hal ini disebabkan oleh terbatasnya ruang dan waktu sehingga dalam subtitling haruslah 'hemat terjemahan'. Dalam penelitian ini, tidak ditemukan penggunaan strategi transkripsi dan angkat tangan (resignation). Dalam penerjemahan subtitling pada film, hendaknya penerjemah selain menguasai strategi penerjemahan, budaya dari bahasa sumber dan bahasa sasaran, juga memperhatikan ketentuan waktu kemunculan subtitling. Hal ini dimaksudkan agar pembaca dapat menangkap secara singkat, tetapi jelas makna dari dialog dalam film tersebut.

Apabila terlalu mentransfer semua kalimat secara harafiah maka waktu tidak akan cukup atau tepat dengan jalannya film. Oleh karena itu, terjemahan film berbeda dengan terjemahan pada teks tertulis seperti novel atau tulisan lain

\section{DAFTAR PUSTAKA}

Baker, M. (1992). In other words: A course on translation. London: Sage Publications.

Bordwell, F., \& Thompson, K. (1990). Film Art. USA: Mc Graw-Hill, Inc.

Catford, J. C. (1965). A linguistic theory of translation: An essay in applied linguistics. Oxford: Oxford University Press.

Gambier, Y. (1993). Audio visual communication: typological detour (Translatio). Philadelphia: John Benjamin.

Gottlieb, H. (1994). Subtitling: Diagonal Translation. In Perspectives: Studies in Translatology. Dinamarca.

Haryanto, S. (2005). Subtitling: Di antara Keterbatasan BahasaBudaya dan Media. Collection of International Conference on Translation: Translation, Discourse and Culture. Program Pascasarjana: UNS. Semarang: Program Pascasarjana: UNS.

Hastuti, E. D. (2015). An Analysis On Subtitling Strategies Of Romeo And Juliet Movie. Register Journal, 8(1), 57-80. Retrieved from

http://journalregister.iainsalatiga 
.ac.id/index.php/register/article/ view/324.

Hoed, B. H. (1992). Linguistik, semiotik, dan kebudayaan kita. Jakarta.

Larson, M. L. (1998). Meaning-based translation: A guide to crosslanguage equivalence (Second Edi). USA: University Press of America, Inc.

Luyken, G.-M., \& Herbst, T. (1991). Overcoming language barriers in television: Dubbing and subtitling for the European audience. Manchester: European Institute for the Media.

Newmark, P. (1981). Approaches to translation (Language Teaching methodology senes). Oxford: Pergamon Press, Ltd.

Nida, E. A., \& Taber, C. R. (1969). The Theory and Practice of Translation, Leiden: EJ Brill. Leiden: E.J Brill.
O'Connell, E. (1998). Choices and constraints in film translation. Unity in Diversity: Current Trends in Translation Studies. Manchester: St. Jerome Publishing, 61-67.

Shuttleworth, M., \& Cowie, M. (1997). Dictionary of translation studies. Manchester: St. Jerome Publishing.

Vinay, J. P., \& Darbelnet, J. (2000). A Methodology for translation in venutti (ed.). The translation study reader. New York: Routledge.

White, B. (2008). Subtitling: The museum of broadcast communication. Translation Journal, 4(1). Retrieved from url:

http://accurapid.com/journal/32f ilm.htm 